\title{
Health risk appraisal in older people 7: long-acting benzodiazepine use in community- dwelling older adults in London: is it related to physical or psychological factors?
}

\section{Devoshree Chatterjee, Steve Iliffe, Kalpa Kharicha, Danielle Harari, Cameron Swift, Gerhard Gillman and Andreas E. Stuck}

University College London, London, UK

\begin{abstract}
Aim: To investigate whether the use of long-acting benzodiazepines, in individuals aged 65 and over is mediated by physical or psychological factors. Background: Long-acting benzodiazepine consumption among older people has implications for mortality, morbidity and cost-effective prescribing. Two models explain benzodiazepine use in this age group, one linked to physical illness and disability and one to psychological factors. Methods: Secondary analysis of baseline data from a study of 1059 communitydwelling non-disabled people aged 65 years and over recruited from three general practices in London. For this analysis, use of long-acting benzodiazepines was defined as any self-reported use of diazepam or nitrazepam in the last four weeks. Associations between demographic factors, health service use, and physical and psychological characteristics and benzodiazepine use were investigated. Findings: The prevalence of benzodiazepine use in this sample was 3.3\% (35/1059). In univariate analyses, benzodiazepine use was associated with female gender, low income, high consultation rates, physical factors (medication for arthritis or joint pain, polypharmacy, difficulties in instrumental activities of daily living, recent pain) and psychological factors (poor selfperceived health, social isolation, and symptoms of anxiety or agitation). In a multivariate logistic regression analysis only two factors retained statistically significant independent associations with benzodiazepine use: receiving only the state pension (OR $=4.0,95 \%$ $\mathrm{Cl}: 1.70,9.80)$ and pain in the past four weeks (OR $=3.79,95 \% \mathrm{Cl}: 1.36,10.54)$.
\end{abstract}

Key words: benzodiazepines; depression; older people; pain

Received 4 July 2016; revised 16 January 2017; accepted 20 January 2017; first published online 22 February 2017

\section{Introduction}

In older people, use of long-acting benzodiazepines are associated with multiple risks, including falls, drowsiness and ataxia, cognitive decline, impaired psychomotor function, and risk of dependence (Voyer et al., 2010). Older adults tend to take long-acting benzodiazepines for longer, risking accumulation and potentiation of their

Correspondence to: Steve Iliffe, FRCGP, University College London, NW3 2PF London, UK. Email: s.iliffe@ucl.ac.uk sedative side effects. The ageing population and polypharmacy with risks of adverse drug effects and drug induced iatrogenesis are contributing to increased demands on the UK National Health Service. Although long-term use of benzodiazepines has been discouraged now for some time (Leipzig et al., 1999), their use continues to be a problem. Therefore, it is vital to ensure benzodiazepine drugs are prescribed appropriately, and for the shortest duration clinically indicated.

Some epidemiological studies of benzodiazepine use in older adults suggest it reflects 
psychological disorder including depression, suicidal ideation, panic disorder, anxiety, memory impairment, poorer self-rated health and poorer life satisfaction (Kirby et al., 1999; Balestrieri et al., 2005; Stowell et al., 2008; Assem-Hilger et al., 2009; Voyer et al., 2009; Rikala et al., 2011), while others suggest it reflects physical illness and disability such as coronary heart disease, hypertension, painrelated joint complaints, smoking, cancer, chronic obstructive pulmonary disease, diabetes and multimorbidity (Dealberto et al., 1997; Gleason et al., 1998; Fourrier et al., 2001; Luijendijk et al., 2008; Cheng et al., 2008; van Eijk et al., 2010). Most studies show higher use in females(Kirby et al., 1999; Jorm et al., 2000; Fourrier et al., 2001; Windle et al., 2007; Cheng et al., 2008) but Mayer-Oakes et al.(1993) and Swartz et al.(1991) showed that use of benzodiazepines was not associated independently with gender, but with physical health status, which was poorer in women than men.

General practitioners managing older people are often faced with the dilemma of treating a symptom or seeking the underlying cause. Knowing more about the reasons behind the use of benzodiazepines by older adults may help develop more appropriate alternative management strategies. Two explanatory models of benzodiazepine use among older adults - the psychological and the physical described above - deserve further investigation. This study aimed to explore the prevalence and characteristics of long-acting benzodiazepine use in a cohort of community-dwelling patients aged 65 years and older and their relationships to the two models. We hypothesised that long-acting benzodiazepine use in the sample population would be associated with physical factors such as arthritis, difficulties in IADL, polypharmacy or pain, or with psychological factors such as depression, anxiety, poor self-perceived health, social isolation, and impaired memory. Following the epidemiological literature, we also hypothesised that female gender, lower educational attainment and increased service use would be positively associated with long-acting benzodiazepine use. Conversely, income above the state pension would have a protective effect.

\section{Methods}

Three large group practices in suburban London were recruited to participate in a multi-centre, multinational randomised controlled trial investigating the effect of Health Risk Appraisal for Older persons (HRA-O) on health behaviours and status (Stuck et al., 2002). Practices located in suburban London, particularly interested in primary care for older people, and using electronic medical recording systems in clinical encounters were purposively selected. A full account of the methodology of the study is available elsewhere (Stuck et al., 2007), including practice size, recruitment of practices and patients, training of general practitioners in health promotion with older people, response rates, use of reminders and the evidence justifying the preventive care recommendations given. This study was part of a three nation RCT of health promotion for older people, and had data capture tools that reflected the consensus of opinion about salient clinical problems.

To identify eligible patients aged 65 years and over, practice lists were cleaned by general practitioners. Eligibility criteria were: those living at home, without (a) evidence of need for human assistance in basic activities of daily living, (b) high dependency due to major physical or psychiatric illness, or cognitive impairment, or (c) a terminal illness. Patients also had to have a sufficient understanding of English to complete the questionnaires. This patient population was further characterised using the Probability of Recurrent Admissions (Pra) questionnaire (Pacala et al., 1995), and asked to complete a consent form by post. The Pra measures risk of hospital admission, and stratifies the population by level of risk for future in-patient care. It was used in the main study as the basis for risk-stratified outcome and analyses.

Eligible and consenting patients were posted the HRA-O questionnaire. The HRA-O is a multidimensional, self-completion questionnaire collecting information on health, functional status, health behaviours, preventive care, and psychosocial factors in older people (Table 1). The development of the HRA-O questionnaire, the derivation of the instruments used in it, the exact definitions of the categories and the feasibility of its use in British primary care have been reported elsewhere (Iliffe et al., 2005). Non-responders to the initial mailing were sent a postal reminder. Those who responded, and those who met the inclusion criteria described above, were included in the study. The findings reported in this paper are from the baseline completion of the questionnaire. 
Table 1 Factors associated with use of long-acting benzodiazepines: univariate analysis and multivariate logistic regression analysis

\begin{tabular}{|c|c|c|c|c|c|c|c|}
\hline Factor & $n(\%)$ & Unadjusted OR & $95 \% \mathrm{Cl}$ & $P$-value & Adjusted OR & $95 \% \mathrm{Cl}$ & $P$-value \\
\hline \multicolumn{8}{|l|}{ Demographics } \\
\hline $\begin{array}{l}\text { Female }(n=583) \\
\text { Male }(n=476)\end{array}$ & $\begin{array}{r}28(5.0) \\
7(1.4)\end{array}$ & 3.380 & $1.463-7.809$ & 0.003 & 2.003 & $0.684-5.861$ & 0.20 \\
\hline Receives solely the state pension $(n=343)$ & $21(6.0)$ & 3.448 & $1.706-6.993$ & 0.001 & 4.081 & $1.698-9.804$ & 0.002 \\
\hline Receives more than state pension $(n=701)$ & $13(1.8)$ & & & & & & \\
\hline Basic education only ${ }^{a}(n=629)$ & $16(2.6)$ & 0.597 & $0.301-1.185$ & 0.14 & & & \\
\hline More than basic education $(n=424)$ & $18(4.2)$ & & & & & & \\
\hline Age 75 or more $(n=463)$ & $20(4.3)$ & 1.749 & $0.885-3.454$ & 0.12 & & & \\
\hline $65-74$ years old $(n=596)$ & $15(2.5)$ & & & & & & \\
\hline \multicolumn{8}{|l|}{ Service use } \\
\hline $\begin{array}{l}\text { Six or more consultations in past } 12 / 12(n=215) \\
\text { Up to five consultations in past } 12 / 12(n=823)\end{array}$ & $\begin{array}{c}14(6.5) \\
212.6\end{array}$ & 2.730 & $1.364-5.462$ & 0.006 & 2.292 & $0.883-5.950$ & 0.09 \\
\hline \multicolumn{8}{|l|}{ 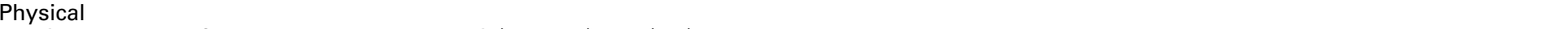 } \\
\hline Taking medicine for joint pain $\geqslant 3$ times/week $(n=219)$ & $15(6.8)$ & 2.984 & $1.490-5.975$ & 0.002 & 0.665 & $0.236-1.872$ & 0.40 \\
\hline Taking medicine for joint pain $<3$ times/week $(n=790)$ & $19(2.4)$ & & & & & & \\
\hline Four or more repeat prescription medications $(n=357)$ & $16(4.5)$ & 1.166 & $1.031-1.319$ & 0.01 & 1.028 & $0.852-1.240$ & 0.77 \\
\hline Up to three repeat medications $(n=686)$ & $19(2.8)$ & & & & & & \\
\hline Diagnosis of arthritis/rheumatism $(n=430)$ & $19(4.4)$ & 1.965 & $0.974-3.963$ & 0.06 & & & \\
\hline No diagnosis of arthritis/rheumatism ( $n=609$ ) & $14(2.3)$ & & & & & & \\
\hline Difficulties in IADL $(n=361)$ & $20(5.5)$ & 3.182 & $1.537-6.587$ & 0.002 & 1.888 & $0.739-4.821$ & 0.18 \\
\hline No IADL difficulties ( $n=663$ ) & $12(1.8)$ & & & & & & \\
\hline Pain in past four weeks & $25(6.2)$ & 6.544 & $2.660-16.103$ & $<0.001$ & 3.787 & $1.361-10.542$ & 0.01 \\
\hline \multicolumn{8}{|l|}{ Psychological } \\
\hline $\begin{array}{l}\text { Symptoms of depression/feeling low }(n=116) \\
\text { No depression/low symptoms }(n=907)\end{array}$ & $\begin{array}{l}10(8.6) \\
23(2.5)\end{array}$ & 1.525 & $1.153-2.017$ & 0.003 & 1.287 & $0.846-1.957$ & 0.24 \\
\hline $\begin{array}{l}\text { Depression (mental mood screen) }(n=150) \\
\text { Negative mental mood screen }(n=888)\end{array}$ & $\begin{array}{l}10(6.7) \\
24(2.7)\end{array}$ & 2.622 & $1.232-5.581$ & 0.01 & 0.843 & $0.264-2.693$ & 0.77 \\
\hline Fair or poor self-perceived health $(n=229)$ & $15(6.6)$ & 2.814 & $1.417-5.590$ & 0.003 & 1.246 & $0.459-3.382$ & 0.67 \\
\hline Good or excellent self-perceived health $(n=823)$ & $20(2.4)$ & & & & & & \\
\hline Socially isolated $(n=146)$ & $9(6.2)$ & 2.213 & $1.016-4.824$ & 0.05 & 1.715 & $0.595-4.946$ & 0.32 \\
\hline Not socially isolated $(n=902)$ & $26(2.9)$ & & & & & & \\
\hline Symptoms of anxiety/agitation & $16(5.2)$ & 1.440 & $1.065-1.947$ & 0.02 & 1.287 & $0.846-1.957$ & 0.24 \\
\hline Impaired memory $(n=102)$ & $3(2.9)$ & 0.845 & $0.254-2.809$ & 0.78 & & & \\
\hline No memory impairment $(n=921)$ & $32(3.5)$ & & & & & & \\
\hline
\end{tabular}


We analysed data from participants who reported using two named long-acting benzodiazepines (diazepam or nitrazepam) in the preceding four weeks. Long-acting benzodiazepines (rather than short-acting ones) were selected because of the high levels of risk associated with their use, including daytime sedation, cognitive and psychomotor impairment, increased risk of falls and fractures, and respiratory depression, particularly in older people (Mendelson, 1992).

These two long-acting benzodiazepines were in common use in the United Kingdom at the time of data collection and are still prescribed today. Both the brand and generic names of the drug were included in the questionnaire.

At baseline, self-reported information on income (state pension only, versus more than state pension) was used as a measure of socio-economic status. Service use was recorded based on selfreported number of visits to the doctor in the prior 12 months.

The following physical characteristics were measured at baseline: assistance with more than one of Lawton's instrumental activities of daily living (IADL) (Lawton and Brody, 1969), polypharmacy (number of prescription medications) and physical activity using the Physical Activity Scale for the Elderly score (Washburn et al., 1993). Pain experience was measured using the Geriatric Pain Measure, a 24-item multidimensional pain questionnaire that uses a 10-point modified Likert scale and also captures the impact of pain on everyday living (Ferrell et al., 2000).

The following psychological factors were measured at baseline: social isolation was measured according to the Lubben Social Network Scale (Lubben et al., 2006), and depressed mood was ascertained with the five-item Mental Health Inventory Screening Test (MHI-5) (Sherbourne and Stewart, 1999), one of the subscales of the Short Form-36 (SF-36), which asks questions about how the person felt during the past month. A score $\leqslant 65$ indicated a depressed mood.

Data were analysed using SPSS (version 19) for Windows to carry out univariate and binary logistic regression analyses as appropriate. In the first stage, $\chi^{2}$ tests were used to explore the associations between any benzodiazepine use in the previous four weeks and the characteristics listed in Table 1. In the second stage of analysis, the variables significantly associated with the use of benzodiazepines in the previous four weeks were entered in a single forward step into a binary logistic regression model.

\section{Results}

In all, 1059 patients aged 65 years and over were included across the three practices. A total of 35 patients reported using a long-acting benzodiazepine (11 nitrazepam, 24 diazepam) in the preceding four weeks, a prevalence of $3.3 \%(35 / 1059)$. Table 1 shows the associations between the selected HRA-O domains and long-acting benzodiazepine use.

Long-acting benzodiazepine users were significantly more likely to be female $(28,80 \%)$. They were also more likely to have visited the doctor more than six times in the past year $(21$ $(60 \%)$ versus $14(47 \%))$, being in receipt of only the state pension $(22(62 \%)$ versus $13(38 \%))$, and be taking medication for arthritis/joint pain $\geqslant 3$ times/week $(15(44 \%)$ versus $7(21 \%))$. No statistically significant differences were found in age or educational attainment.

Long-acting benzodiazepine users were significantly more likely to report needing help with IADL $(63 \%$ versus $34 \%)$, have poorer selfperceived health ( $43 \%$ versus $21 \%$ ), higher risk of social isolation ( $26 \%$ versus $14 \%$ ), report pain in the previous four weeks ( $81 \%$ versus $39 \%)$, and score lower on the mental mood screen $(29 \%$ versus $13 \%)$. In all, $6 \%$ of benzodiazepine users stated they often or always experienced symptoms of depression or feeling low, compared with $2 \%$ of non-benzodiazepine users; $3 \%$ of patients using long-acting benzodiazepines stated they often or always experienced symptoms of anxiety or agitation, compared with $1.5 \%$ of non benzodiazepine users. Long-acting benzodiazepine users were more likely to have poorer self-perceived health $(43 \%$ versus $21 \%)$, higher risk of social isolation ( $26 \%$ versus $14 \%)$, report pain in the previous four weeks ( $81 \%$ versus $39 \%)$, and score lower on the mental mood screen $(29 \%$ versus $13 \%)$. No difference was found in cognitive impairment.

In multivariate analysis (see Table 1) only two factors remained significantly associated with use of long-acting benzodiazepines; higher socioeconomic status as determined by receiving more 
than solely the state pension, and pain in the past four weeks.

\section{Discussion}

The prevalence of use of diazepam and nitrazepam in this sample of older adults is 3.3\%. Long-acting benzodiazepine use in this sample of older people is not independently associated with physical factors such as arthritis, difficulties in IADL or polypharmacy, or with psychological factors such as depression, anxiety, poor self-perceived health, social isolation, and impaired memory. It is independently associated with low income and pain, particularly pain which causes depressive symptoms.

The use of long-acting benzodiazepines in our sample population appears related to a socioeconomic factor - pension level - and also to a physical symptom, pain. It raises the question whether in such cases treating the cause of pain in the form of pain-specific treatment approaches, would be more appropriate than using benzodiazepines.

\section{Strengths and limitations of the study}

This was an in depth study of communitydwelling older adults in an area which is surprisingly under-researched. However, the prevalence of patients using long-acting benzodiazepines in this community-dwelling was $3.3 \%$, which is lower of that found in many (but not all) studies in other western countries. The findings therefore need to be treated tentatively. This low prevalence may be attributable to the fact that long-term benzodiazepine use has been actively discouraged for some time now in the United Kingdom, particularly in older adults, and so represents a success story for general practice. It may also reflect the selfselected nature of the patients in the sample, who had joined a trial on health promotion, or selfselection by high-performing general practices with a special interest in health promotion in older people.

Second, due to the cross-sectional nature of the data, it is not possible to establish causality in the relationships between long-acting benzodiazepine use and the factors associated with it. Also, the number of cases and the number of variables in the statistical model may have resulted in the exclusion of some variables that would have been independently associated in a larger sample.

Third, there are some limitations related to the generalizability of the findings of this study to other populations. The sample was drawn from three general practices in suburban London with a predominantly white population, the results of which may differ from that of rural general practice patients, ethnic minorities or institutionalised patients. We cannot rule out a selection bias in recruitment of older people who may be more motivated to return lengthy questionnaires. The question related to long-acting benzodiazepine use covered only the preceding four weeks and thus, we may have missed patients who had recently discontinued, and we could not distinguish between short- and long-term users. We did not have information on whether the prescription was written by the patient's GP, psychiatrist or other specialist; the dosage, quantity, time point in the course of long-acting benzodiazepine treatment and total duration prescribed; indications and proportion of medication used as regular and 'as needed'. Only the use of long-acting benzodiazepines (diazepam and nitrazepam) was examined, and short-acting benzodiazepines were not included. Against these limitations, the study had access to a relatively large sample size with homogeneity in many characteristics including age and background, and a high response rate, strengthening its internal validity.

\section{Comparison with existing literature}

Most other studies have included a wider range of benzodiazepines than we did. In 1999 in Ireland, Kirby et al. found prevalence rates of $17.3 \%$ for subjects of a similar age group to our study (Kirby et al., 1999). A French study (Fourrier et al., 2001) in 2001 revealed that $32 \%$ of its 2972 communitydwelling subjects were using benzodiazepines at baseline. In Sweden, Johnell and Fastbom (2009) reported that $25 \%$ of patients aged 75 or over used one or more, and 5\% used two or more benzodiazepines and benzodiazepine related drugs. More recently a Finnish study based on data collected from the population-based GeMS (Geriatric multidisciplinary strategy for the good care for the Elderly) project, analysed data from 700 participants aged 75 and over and found a

Primary Health Care Research \& Development 2017; 18: 253-260 
baseline prevalence rate of $31 \%$ at baseline, of which $55 \%$ reported continued use in three further follow-ups (Rikala et al., 2011). Our findings are consistent with those of population-based studies from several countries which suggest rates of benzodiazepine use range from $3 \%$ to $17 \%$ with rates typically higher among older than younger people (Cunningham et al., 2010). In a study conducted in UK Primary care, De Wilde et al. (2007) found that although $5.2 \%$ of older adults were still receiving benzodiazepines in 2003, prescription of benzodiazepines had fallen by a third from 79.3/1000 in 1994 to $52.4 / 1000$ in 2003.

When Luijendijk et al. (2008) studied determinants of long-term benzodiazepine use, they found pain from joint disorders also increased the risk of long-term benzodiazepine use. People with lower socio-economic status receive a higher number of prescriptions than do those of higher socio-economic status (van Eijk et al., 2010). Furthermore, Odubanjo et al. (2004) compared the quality of prescribing between a primary care cohort of 66521 relatively deprived and 28534 affluent patients over 70 years old in Ireland and found a statistically significant higher percentage of the deprived cohort were prescribed a long-acting benzodiazepine drug. This finding is consistent with the findings from our study.

\section{Implications for future practice and research}

Inappropriate use of benzodiazepines remains a concern, internationally (Campanelli, 2012; Préville et al., 2012; Olfson et al., 2015). The findings of this study support the recommendation made elsewhere that primary care practitioners should enquire routinely about pain when seeing older adults in general practice (Carmaciu et al., 2007). Good management of pain may avoid inappropriate use of long-acting benzodiazepines and reduce the risks of their associated morbidities. Future research could include analysis of a larger data set to explore further the relationship between pain and specific long-acting benzodiazepine use, and also explore the relationships between shorter-acting benzodiazepines (and newer equivalents) and pain.

\section{Conclusion}

A multidimensional approach to assessing and managing the circumstances and symptoms Primary Health Care Research \& Development 2017; 18: 253-260 associated with potentially inappropriate benzodiazepine use appears justified in communitydwelling older people. Appropriate treatment of pain may further reduce the use of benzodiazepines in older patients.

\section{Acknowledgements}

The authors thank the patients and practices involved in the study.

\section{Financial Support}

European Commission project QLK6-CT-199902205 and the Federal Education Science Ministry, Berne, Switzerland (BBW 990311.1).

\section{Ethical Standards}

Approval was obtained from Brent Medical Ethics Committee (BEC 745) and King's College Hospital Research Ethics Committee (01-010).

\section{Conflicts of Interest}

The authors have stated that there are none.

\section{References}

Assem-Hilger, E., Jungwirth, S., Weissgram, S., Kirchmeyr, W., Fischer, P. and Barnas, C. 2009: Benzodiazepine use in the elderly: an indicator for inappropriately treated geriatric depression? International Journal of Geriatric Psychiatry 24, 563-69.

Balestrieri, M., Marcon, G., Samani, F., Marini, M., Sessa, E., Gelatti, U. and Donato, F. 2005: Mental disorders associated with benzodiazepine use among older primary care attenders - a regional survey. Social Psychiatry and Psychiatric Epidemiology 40, 308-15.

Campanelli, C.M. 2012: American geriatrics society updated beers criteria for potentially inappropriate medication use in older adults: The American Geriatrics Society 2012 Beers Criteria Update Expert Panel. Journal of the American Geriatrics Society 60, 616-31.

Carmaciu, C., Iliffe, S., Kharicha, K., Harari, D., Swift, C., Gillmann, G. and Stuck, A.E. 2007: Health risk appraisal in older people 3: prevalence, impact, and context of pain and their implications for GPs. British Journal of General Practice 57, 630-35.

Cheng, J.S., Huang, W.F., Lin, K.M. and Shih, Y.T. 2008: Characteristics associated with benzodiazepine usage in elderly outpatients in Taiwan. International Journal of Geriatric Psychiatry 23, 618-24. 
Cunningham, C.M., Hanley, G.E. and Morgan, S. 2010: Patterns in the use of benzodiazepines in British Columbia: examining the impact of increasing research and guideline cautions against long-term use. Health Policy 97, 122-29.

Dealberto, M.J., Seeman, T., McAvay, G.J. and Berkman, L. 1997: Factors related to current and subsequent psychotropic drug use in an elderly cohort. Journal of Clinical Epidemiology 50, 357-64.

De Wilde, S., Carey, I.M., Harris, T., Richards, N., Victor, C., Hilton, S.R. and Cook, D.G. 2007: Trends in potentially inappropriate prescribing amongst older UK primary care patients. Pharmacoepidemiology and Drug Safety 16, 658-67.

Ferrell, B.A., Stein, W.M. and Beck, J.C. 2000: The Geriatric Pain Measure: validity, reliability and factor analysis. Journal of the American Geriatrics Society 48, 1669-673.

Fourrier, A., Letenneur, L., Dartigues, J.F., Moore, N. and Begaud, B. 2001: Benzodiazepine use in an elderly community-dwelling population. Characteristics of users and factors associated with subsequent use. European Journal of Clinical Pharmacology 57, 419-25.

Gleason, P.P., Schulz, R., Smith, N.L., Newsom, J.T., Kroboth, P.D., Kroboth, F.J. and Psaty, B.M. 1998: Correlates and prevalence of benzodiazepine use in community-dwelling elderly. Journal of General Internal Medicine 13, 243-50.

Iliffe, S., Kharicha, K., Harari, D., Swift, C. and Stuck, A.E. 2005: Health risk appraisal for older people in general practice using an expert system: a pilot study. Health \& Social Care in the Community 13, 21-29.

Johnell, K. and Fastbom, J. 2009: The use of benzodiazpines and related drugs amongst older people in Sweden: associated factors and concomitant use of other psychotropics. International Journal of Geriatric Psychiatry 24, 731-38.

Jorm, A.F., Grayson, D., Creasey, H., Waite, L. and Broe, G.A. 2000: Long-term benzodiazepine use by elderly people living in the community. Australian and New Zealand Journal of Public Health 24, 7-10.

Kirby, M., Denihan, A., Bruce, I., Radic, A., Coakley, D. and Lawlor, B.A. 1999: Benzodiazepine use among the elderly in the community. International Journal of Geriatric Psychiatry 14, 280-84.

Lawton, M.P. and Brody, E.M. 1969: Assessment of older people: self-maintaining and instrumental activities of daily living. The Gerontologist 9, 179-86.

Leipzig, R.M., Cumming, R.G. and Tinetti, M.E. 1999: Drugs and falls in older people: a systematic review and metaanalysis: I. Psychotropic drugs. Journal of the American Geriatrics Society 47, 30-39.

Lubben, J., Blozik, E., Gillmann, G., Iliffe, S., von Renteln Kruse, W., Beck, J.C. and Stuck, A.E. 2006: Performance of an abbreviated version of the Lubben Social Network Scale among three European community-dwelling older adult populations. The Gerontologist 46, 503-13.

Luijendijk, H.J., Tiemeier, H., Hofman, A., Heeringa, J. and Stricker, B.H. 2008: Determinants of chronic benzodiazepine use in the elderly: a longitudinal study. British Journal ofClinical Pharmacology 65, 593-99.
Mayer-Oakes, S.A., Kelman, G., Beers, M.H., De Jong, F., Matthias, R., Atchison, K.A., Lubben, J.E. and Schweitzer, S.O. 1993: Benzodiazepine use in older, community-dwelling southern Californians: prevalence and clinical correlates. Annals of Pharmacotherapy 27, 416-21.

Mendelson, W.B. 1992: Clinical distinctions between longacting and short-acting benzodiazepines. The Journal of Clinical Psychiatry 53, 4-7.

Odubanjo, E., Bennett, K. and Feely, J. 2004: Influence of socioeconomic status on the quality of prescribing in the elderly - a population based study. British Journal of Clinical Pharmacology 58, 496-502.

Olfson, M., King, M. and Schoenbaum, M. 2015: Benzodiazepine use in the United States. JAMA Psychiatry 72, 136-42.

Pacala, J.T., Boult, C. and Boult, L. 1995: Predictive validity of a questionnaire that identifies older persons at risk for hospital admission. Journal of the American Geriatrics Society 43, 374-77.

Préville, M., Bossé, C., Vasiliadis, H.-M., Voyer, P., Berbiche, D., Pérodeau, G., Grenier, S., Béland, S.-G., Dionne, P.-A., Gentil, L. and Moride, Y. 2012: Correlates of potentially inappropriate prescriptions of benzodiazepines among older adults: results from the ESA study. Canadian Journal on Aging 31, 313-22.

Rikala, M., Korhonen, M.J., Sulkava, R. and Hartikainen, S. 2011: Psychotropic drug use in community-dwelling elderly people-characteristics of persistent and incident users. European Journal of Clinical Pharmacology 67, 731-39.

Sherbourne, C.D. and Stewart, A.L. 1999: The MOS social support survey. Social Science and Medicine 32, 705-14.

Stowell, K.R., Chang, C.C., Bilt, J., Stoehr, G.P. and Ganguli, M. 2008: Sustained benzodiazepine use in a community sample of older adults. Journal of the American Geriatrics Society 56, 2285-291.

Stuck, A.E., Elkuch, P., Dapp, U., Anders, J., Iliffe, S. and Swift, C.G. 2002: Feasibility and yield of a self-administered questionnaire for health risk appraisal in older people in three European countries. Age and Ageing 31, 463-67.

Stuck, A.E., Kharicha, K., Dapp, U., Anders, J., von Renteln-Kruse, W., Meier-Baumgartner, H.P., Iliffe, S., Harari, D., Bachmann, M.D., Egger, M., Gilmann, G., Beck, J.C. and Swift, C.G. 2007: The PRO-AGE study: an international randomised controlled study of health risk appraisal for older persons based in general practice. $B M C$ Medical Research Methodology 7, 2.

Swartz, M., Landerman, R., George, L.K., Melville, M.L., Blazer, D. and Smith, K. 1991: Benzodiazepine anti-anxiety agents: prevalence and correlates of use in a southern community. American Journal of Public Health 81, 592-96.

van Eijk, J.T., Bosma, H., Jonkers, C.C., Lamers, F. and Muijrers, P.E. 2010: Prescribing antidepressants and benzodiazepines in the Netherlands: is chronic physical illness involved? Depression Research and Treatment 2010, 105931.

Voyer, P., Preville, M., Cohen, D., Berbiche, D. and Beland, S.G. 2010: The prevalence of benzodiazepine dependence 
among community-dwelling older adult users in Quebec according to typical and atypical criteria. Canadian Journal on Aging $=L a$ revue canadienne $d u$ vieillissement 29, 205-13.

Voyer, P., Preville, M., Roussel, M.E., Berbiche, D. and Beland, S.G. 2009: Factors associated with benzodiazepine dependence among community-dwelling seniors. Journal of Community Health Nursing 26, 101-13.
Washburn, R.A., Smith, K.W., Jette, A.M. and Janney, C.A. 1993: The Physical Activity Scale for the Elderly (PASE): development and evaluation. Journal of Clinical Epidemiology 46, 153-62.

Windle, A., Elliot, E., Duszynski, K. and Moore, V. 2007: Benzodiazepine prescribing in elderly Australian general practice patients. Australian and New Zealand Journal of Public Health 31, 379-81. 